\title{
Application of High Energy-resolution Silicon Drift Detectors (SDD) for Quantitative Light Element Analysis
}

\author{
Ralf Terborg, Martin Rohde \\ RÖNTEC GmbH, Schwarzschildstr. 12, D-12489 Berlin, Germany
}

Within recent years, advances in the field of X-ray detection are marked by two outstanding developments: the cryogenic detectors (microcalorimeter, STJ) on one hand and the Silicon Drift Detectors (SDD) on the other hand. While cryogenic detectors up to now are affordable only for high-end applications, the SDD technology aims at lightweight, user-friendly, and readily available systems with reasonable performance. SDD spectrometers are meanwhile well established in many fields, not at least because of their extraordinary count-rate capability of up to one million counts per second at good or moderate energy resolution.

The aim of this contribution is to show that the SDD technology is not only an ideal solution for mapping and imaging applications but also enables light element analysis and quantification in Xray microanalysis at the scanning electron microscope (SEM). On practical examples, it is shown that it is possible to match or even outperform the classical Si(Li) spectrometer, using a state-of-theart $3^{\text {rd }}$ generation XFlash ${ }^{\circledR}$ spectrometer.

The key factor for X-ray light element analysis is the radiation entrance window. Because of the low transparency of matter for X-rays in the range of $1 \mathrm{keV}$ and below, ultra thin windows are required. Other prerequisites for accurate light element analysis are superior energy resolution and stable spectral performance.

The traditional energy resolution benchmarks of the proven $\mathrm{Si}(\mathrm{Li})$ technology could recently be defeated by modern Drift Detector Droplets $\left(\mathrm{SD}^{3}\right)$ in all ranges of count rate and quantum energy (Fig. 1). Additionally, electronic noise and FANO-factor exhibit slight advantages with $\mathrm{SD}^{3}$ detectors (Tab. 1). Both directly have a positive effect on peak deconvolution and background correction, which is vital in the field of light element analysis due to the characteristic line overlaps. Peak deconvolution and background estimation of course also benefit from the higher count rate capability, since the statistical relevance of a measured spectrum rises with the number of total counts.

The comparative high tail and shelf effect characteristic for SDD detectors was, for a long time, considered a limiting factor for light element analysis. The $\mathrm{SD}^{3}$ technology partly removes this problem by having changed the detector design (Fig. 2). Besides technological improvements, the key factor however is, that meanwhile the physical processes have been investigated and are well understood. Proper physical modeling allows canceling of these effects by calculations even during the measurement process (Fig. 3). The achieved spectra exhibit only minor artifacts and are well suited for evaluation by standard EPMA and XRF quantification routines (Fig. 4).

\section{References}

[1] R. Hartmann et al., Metrologia 32 (1996) 491

[2] R. Hartmann et al., Nucl. Instr. and Meth. A 377 (1996) 191

[3] F. Scholze, M. Procop, X-ray Spectrom. 30 (2001) 69 


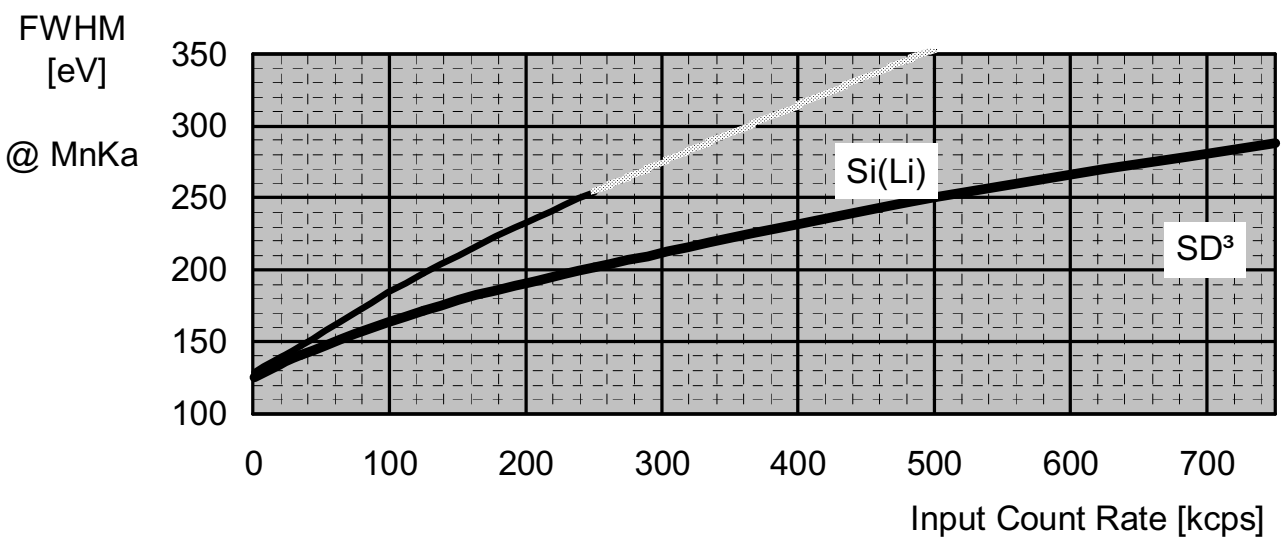

Fig. 1. Energy Resolution (FWHM) of $\mathrm{SD}^{3}$ Detectors and state-of-the-art $\mathrm{Si}(\mathrm{Li})$

Table 1. Energy Resolution of different Silicon Semiconductor Detectors

\begin{tabular}{|cccc|}
\hline & Electronic noise & FANO & $@ M_{n} \mathbf{K}_{\boldsymbol{\alpha}}$ \\
\hline Si(Li) & $42 \mathrm{eV}$ & 0.120 & $129 \mathrm{eV}$ \\
PIN & $119 \mathrm{eV}$ & 0.118 & $170 \mathrm{eV}$ \\
SD $^{3}$ & $39 \mathrm{eV}$ & 0.117 & $127 \mathrm{eV}$ \\
\hline
\end{tabular}

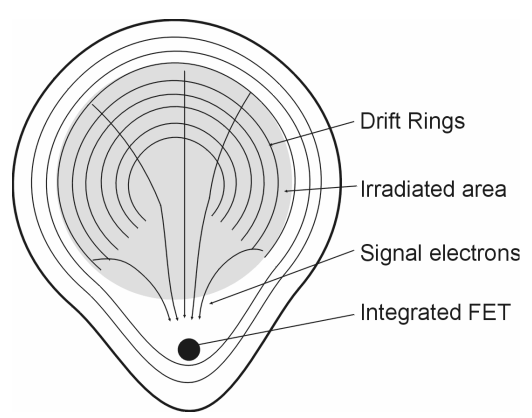

Fig. 2. Silicon Drift Detector Droplet $\left(\mathrm{SD}^{3}\right)$

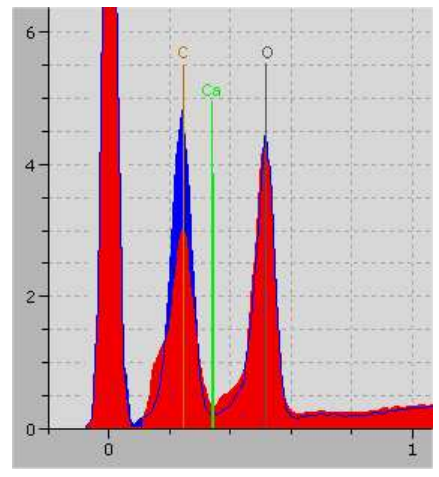

Fig. 3. Physical Modeling of Tail and Shelf

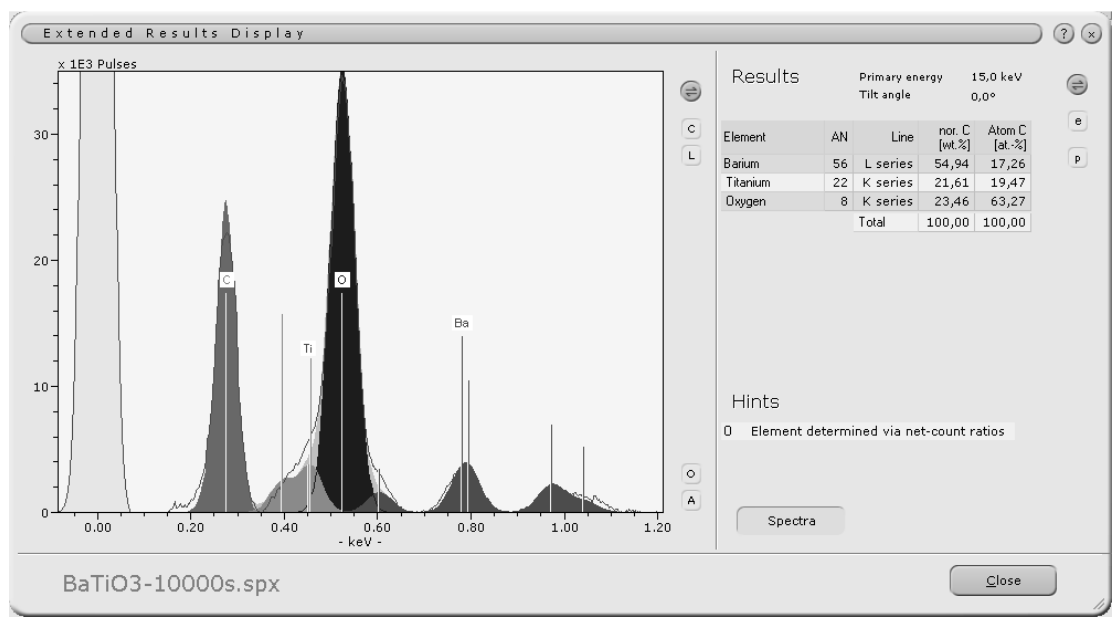

Fig. 4. Analysis of Bariumtitanate using an $\mathrm{SD}^{3}$ Spectrometer (Example) 